$\begin{array}{ll} & \text { Etnográfica } \\ \text { etnográfica } & \text { Revista do Centro em Rede de Investigação em }\end{array}$

Antropologia

vol. $26(1) \mid 2022$

Vol. $26(1)$

\title{
(Arte)sanato tradicional: fricções entre matrizes de pensamento
}

Traditional (art)craft: frictions between thought matrices

\section{Daniel Reis}

\section{(2) OpenEdition}

\section{Journals}

\section{Edição electrónica}

URL: https://journals.openedition.org/etnografica/11464

DOI: 10.4000/etnografica. 11464

ISSN: 2182-2891

\section{Editora}

Centro em Rede de Investigação em Antropologia

\section{Edição impressa}

Paginação: 209-231

ISSN: 0873-6561

\section{Refêrencia eletrónica}

Daniel Reis, «(Arte)sanato tradicional: fricções entre matrizes de pensamento», Etnográfica [Online], vol. 26 (1) | 2022, posto online no dia 25 fevereiro 2022, consultado o 30 junho 2022. URL: http:// journals.openedition.org/etnografica/11464; DOI: https://doi.org/10.4000/etnografica. 11464

\section{(c) (†) (8)}

Etnográfica is licensed under a Creative Commons Attribution-NonCommercial 4.0 International License. 


\section{(Arte)sanato tradicional: fricções entre matrizes de pensamento}

\section{Daniel Reis}

A importância atribuída ao chamado artesanato tradicional é notória no mundo contemporâneo. Tais objetos mobilizam uma extensa rede de pessoas, instituições, políticas públicas, com motivações e objetivos diversos. Este artigo visa uma análise de quatro matrizes discursivas sobre $\mathrm{o}$ artesanato tradicional que se consolidaram a partir de meados do século xx no Brasil. Pretende indicar suas principais características, atores sociais, estratégias de ação e desdobramentos contemporâneos.

PALAVRAS-CHAVE: artesanato tradicional, objetos, cultura popular, arte popular.

Traditional (art)craft: frictions between thought matrices - The importance given to the so-called traditional artisanship is noticeable around the world nowadays. Such objects mobilise a large network of people, institutions and public policies with different motivations and objectives. This article has as its objective analysis of four main discursive matrices towards traditional artisanship, which have strengthened in the mid-20 ${ }^{\text {th }}$ century in Brazil. This study aims to appoint its main characteristics, social agents, strategies and repercussions in traditional artisanship field in the current context.

KEYWORDS: traditional artisanship, objects, popular culture, popular art.

REIS, Daniel (drreis55@yahoo.com.br) - Centro Nacional de Folclore e Cultura Popular, Brasil. 


\section{INTRODUÇÃO}

"A gente precisa mostrar a nossa especificidade dentro de tantos artesanatos [...]. [Nós] temos que atentar para esse artesanato de identidade tradicional. O valor está para além do preço, essa é a nossa luta, o valor foi dado primeiro. É a tradição. É a história.” (apud. Nascimento 2016)

Mais que um objeto, tradição e história. É para o que chama a atenção a fala de Ana, artesã que trabalha com o capim dourado no Jalapão, Tocantins, sublinhando os valores associados ao que produzem. Saberes transmitidos geracionalmente sobre o manuseio da matéria-prima, estética, redes de interação e memórias de uma localidade internacionalmente conhecida por sua cobiçada produção artesanal. Não por acaso, a ênfase: ali, não produzem qualquer manufatura, mas sim o chamado artesanato de cunho tradicional.

Os objetos possuem importante papel na formação de perceções individuais e coletivas. São bons para pensar, além da materialidade, a teia de relações humanas que desencadeiam e da qual fazem parte; os sistemas de classificação a que estão submetidos e a partir dos quais são acionados. Acompanhar seus deslocamentos físicos e simbólicos, os delineamentos destes contextos, suas permanências e instabilidades, são caminhos para compreender as dinâmicas da vida social e cultural, suas tensões, ambiguidades e paradoxos (Gonçalves 2007; Hoskins 1998; Kopytoff 1986).

Este texto se debruça sobre objetos que, em certos circuitos e redes relacionais, são acionados como "artesanato tradicional", com foco no contexto brasileiro. Frequentemente descritos por sua diversidade e potencial criativo, materializam saberes, formas de expressão envolvendo ainda performances, ritualizações, memórias e narrativas. Seus autores são designados por adjetivações como artífices e mestres, forma de destacar o notório saber sobre um bem cultural justificado por critérios como inventividade e/ou ancestralidade. São majoritariamente mulheres, em inúmeras localidades do país e que, por meio desta produção, fomentam a chamada economia criativa, gerando renda para inúmeras famílias, impulsionando o turismo, feiras e exposições (Firjan 2019).

As iniciativas voltadas para o artesanato tradicional alavancaram a partir da segunda metade do século xx. Hoje, há uma extensa e complexa rede composta por instituições de distintas esferas governamentais, ONG, iniciativa privada e pessoas. Suas estratégias de ação oscilam, ora tendendo a pensá-lo enquanto reminiscência de um mundo em vias de desaparecimento, ora como potência criativa motriz no mundo moderno. Ora como possibilidade de ascensão econômica, ora como singular expressão simbólica. Ora como patrimônio cultural, ora como produto. E ainda, entre discursos de descoberta e assistencialistas.

Neste emaranhando é notório que se consolidaram no Brasil, do ponto de vista institucional, quatro principais matrizes discursivas de criação e atuação 
sobre o artesanato tradicional: a do desenvolvimento econômico, a do design, a que valoriza memórias e saberes, e a que se desloca da arte popular à arte contemporânea. Longe de se oporem, são discursos entrecruzados, em permanente tensão e que articulam a circulação de objetos ditos de cunho tradicional em redes de interações materiais e simbólicas distintas. Desdobram-se e reformulam-se ao longo do tempo com maior ou menor força, atualizando seu repertório teórico e o capital político e simbólico.

Se os objetos despertam afetos, memórias e disputas, compreender como circulam e são acionados discursivamente é algo relevante. Afinal, por que no mundo contemporâneo fala-se tanto em artesanato? Quais as especificidades de seu qualificativo tradicional? Porque tantas instituições se interessam por classificar e agir sobre ele? Qual é a rede de atores sociais envolvidos? Com que interesses?

O objetivo deste texto é analisar como se constituíram as citadas matrizes de discursos autorizados (Smith 2006) sobre artesanato tradicional no Brasil. Como foram elaborados e chancelados por instituições e especialistas constituindo narrativas hegemônicas sobre um dado campo de conhecimento. ${ }^{1}$ Metodologicamente, este artigo se pauta, para além da revisão bibliográfica, por uma etnografia de arquivos. Da observação, descrição, interpretação e análise de um conjunto de questões, do ponto de vista antropológico, a partir de fundos documentais. Os arquivos, tal como museus e demais instituições culturais, são lugares de disputas, tensões, temporalidades, elaboração e contestação de narrativas sobre passados e culturas. De tal modo potentes espaços de pesquisa, análise e transformação social (Cunha 2004; Gonçalves 2007; Heymann 2013).

De modo específico, esta pesquisa partiu dos arquivos do Centro Nacional de Folclore e Cultura Popular (CNFCP), que será mais bem apresentado à frente. De antemão, cabe dizer que se trata de um acervo reunido a partir de meados do século xx por pesquisadores ligados ao campo de estudos do folclore e culturas populares. Engloba arquivos pessoais de folcloristas e antropólogos, projetos e manuscritos sobre memória institucional, para além de uma hemeroteca especializada no tema. Estes documentos têm sido fonte indispensável de pesquisas sobre ritos, festas, biografias, patrimonialização, entre outros temas. Observá-los tendo como foco o artesanato dito tradicional soma-se aos esforços por trazer novas leituras sobre tais e ao campo de estudos a que se referem. Enquanto parte do quadro técnico do CNFCP, este texto reflete também minhas experiências e motivações em dar maior publicidade a este acervo do qual muito ainda há para ser estudado. 


\section{FRICÇÕES SOBRE O (ARTE)SANATO TRADICIONAL}

Artesanato costuma ser descrito como resultado do trabalho manual associado ao apuro técnico e liberdade criativa de seu autor. Abrange diversas tipologias the rendendo adjetivações como tradicional, indígena, conceitual, entre outros. Artesanato ou artesanatos? (Lima 2010). A literatura sobre o tema é consensual sobre tratar-se de objetos com ritmo próprio de produção ligado à sazonalidade da matéria-prima; dotados de forma única e perfeitamente irregular; em reelaboração permanente; autorais e portadores de valores culturais e afetivos; que guardam caráter intersubjetivo, convidando ao toque e interação. É parte de intrincadas redes de significados e os valores a ele atribuídos mudam à medida que circula entre o contexto em que é produzido e aquele em que é exibido e/ou consumido (Canclini 1998; Lima 2010; Paz 1991).

Richard Sennett (2009) recorda que, em diferentes momentos da história ocidental, a atividade prática foi menosprezada em relação a ocupações ditas elevadas resultando em equivocadas análises sobre o trabalho manual. Sua sugestão é pensar o artesanato por outro caminho, como engajamento. Aspetos como a repetição são formas de aprimoramento, descoberta, criação e autoconhecimento. O sujeito cria a si mesmo na medida em que (re)cria e refina sua técnica e repertório. $\mathrm{O}$ artesanato é, assim, sempre contemporâneo e inventivo.

Somado à adjetivação tradicional, o artesanato ganha contornos semânticos específicos. Há um considerável debate sobre tradição, em que essa noção é pensada recorrentemente em relação ao seu suposto antagônico, modernidade (Anderson 1991; Hobsbawm e Ranger 2002). Essa percepção dicotômica é acionada para enfatizar questões como distintos regimes de historicidade (Hartog 2006). Entre os que se baseiam no futuro, progresso, racionalidade, recriação contínua; e os que se aportam no passado como atualização cíclica, conservação, risco de desaparecimento. Tradição, mais do que remeter a um outro tempo e espaço, é a forma retórica sobre como o moderno Ocidente construiu uma invenção de si supostamente apartado, ele próprio, de um dado momento do passado.

O mundo pós-colonial acentuou as discussões sobre "o complexo problema de transmissão cultural” (Phillips 2004), afora o já reconhecido caráter dinâmico de qualquer expressão. Mark Phillips atenta para as nuances que a "tradição" pode ter em contextos comunais, para além dos discursos nacionais. Argumenta que ela opera também por quebras, traduções, superações de contradições. Mesmo mudanças abruptas e/ou revolucionárias não significam, necessariamente, perda da tradição. Podem se referir à habilidade de grupos em superar adversidades configurando novos conhecimentos.

James Clifford (2004) sugere pensar tradição como articulação, uma alternativa para a compreensão das (re)construções dos tradicionalismos. Seu argumento é o de que os ecos descoloniais colocaram em xeque as perspectivas de 
"tradições inventadas" e autenticidade como vinham sendo debatidas. Advoga que tradição atualmente não se refere a busca por formas integrais do passado, mas a seleção crítica e estratégica destas memórias. Ela se tornou assim um tenso, criativo, aberto e produtivo modo de articulação no presente sobre interconectados futuros.

Com base nesta discussão, pode ser rentável pensar o artesanato tradicional como um engajamento criativo em constante reelaboração que articula circuitos de saberes, passados, valores e culturas, acionados discursivamente num dado presente por distintas redes e atores sociais para tensionar e agir sobre determinadas realidades. Está sempre envolto em camadas de produção de sentido que vão do mais elaborado grau de racionalidade e institucionalidade até à dimensão subjetiva e sensível.

Essas dissonâncias se adensam considerando as fricções entre os termos artesanato, artesanato tradicional, arte, arte popular. É longevo, por exemplo, o debate sobre arte e artesanato em que se atribui à primeira características como unicidade, originalidade, intelectualidade, autoria, especialização; e ao segundo série, conjunto, coletivo, anonimato, manualidade (Canclini 1998; Sennett 2009). Em tempos recentes, estas distinções se refinaram e englobam um complexo sistema de arte e patrimônio (Reis 2018).

Sobre as fricções entre arte e arte popular, cabe comentar que se atribui a esta última características como produção realizada a partir da experiência, criatividade e imaginário de seu autor, dispensando um aprendizado formal acadêmico, frequentemente associado a narrativas de descoberta e ancestralidade (Lima e Waldeck 2016). As barreiras de circulação entre ambas vêm sendo borradas e nota-se um crescente número de indivíduos antes circunscritos à alcunha popular, transitando nos mundos da arte contemporânea. Por um lado, isso está ligado a uma busca no campo da arte por romper fronteiras geográficas, temporais e superar adjetivações e estigmatizações hegemônicas. Por outro, à valorização econômica das obras de arte popular em patamares sem precedentes. É notório, no entanto, que os objetos parecem ter alcançado uma circulação e valorização no mercado de arte que os seus autores permanecem aquém, muitos vivendo ainda em precárias condições. $\mathrm{O}$ reconhecimento simbólico nos mundos de arte (Becker 2010) não refletiu ainda um sistema de relações mais equânime do ponto de vista econômico (Reis 2018).

As interações da arte popular com a arte contemporânea jogam luz em outra "fronteira": entre arte popular e artesanato tradicional. Categorias ambíguas, frequentemente usadas de modo indistinto, nota-se nos últimos anos o impulso de uma vertente que enfatiza a diferença - como será exposto à frente. Neste caso, sublinha-se que a arte popular retrata o imaginário e formas de ver o mundo de um autor em objetos únicos por comparação a uma pretensa característica serial e tendência ao coletivo do artesanato tradicional. Quanto a isto, cabe lembrar que, de um lado, o artesanato envolve um tipo 
de engajamento e recriação constante que torna cada peça única. Por outro, mesmo a mais institucionalizada arte pode envolver obras em série e o trabalho em conjunto. Como sublinha Becker (2010), arte é sempre um trabalho coletivo e permeado por redes e interações.

Há ainda as tensões entre o artesanato nos sentidos amplo e tradicional. Neste caso, argumenta-se que o último se distingue dos demais visto que ligado a saberes transmitidos geracionalmente, e que seus valores simbólicos e identitários importam mais do que os mercadológicos (Lima 2010). As fronteiras que definem quando um objeto é digno de receber a alcunha tradicional, no entanto, são turvas e não raro arbitrárias. Sob este viés, estes objetos podem alcançar ainda outros sistemas de valores, como patrimônios culturais e marcas coletivas, por exemplo.

Isto posto, nota-se que um mesmo objeto e autor podem ser acionados em várias redes relacionais por distintas categorias. As obras de Antônio de Dedé, reconhecido escultor alagoano, foram classificadas como arte, artesanato tradicional, patrimônio, enquanto o próprio seguiu dizendo que fazia "seus personagens", referindo-se a uma forma de ver e recriar seu mundo (Reis 2010). Percepções subjetivas, categorias políticas, disciplinares e institucionais que buscam organizar a vida pública e construir imaginários coletivos, longe de opostas, se cruzam a todo o tempo. É sobre o potencial criativo e transformador de suas reelaborações que os discursos sobre artesanato tradicional se tornam relevantes para pensar.

\section{O DISCURSO DO DESENVOLVIMENTO ECONÔMICO}

O discurso desenvolvimentista para o artesanato tradicional se caracteriza pela forte inclinação econômica. A atividade artesanal é vista como geradora de trabalho e renda sobretudo nas áreas mais pobres do país. Ainda que reconheça a diversidade, especificidades regionais, saberes e memória cultural de cada artesanato, a ênfase é no produto, imbuído da aura de genuína brasilidade e agregação de valor financeiro. São frisadas intervenções ditas de qualificação e adequação ao mercado, à organização em cooperativas e ao fomento ao comércio internacional. Seu desdobramento recente enfatiza o reconhecimento do artesão enquanto categoria de ofício buscando meios para atender às suas demandas e a melhor equalização na relação mercado e cultura.

Essa via de pensamento sobre o artesanato surgiu na passagem dos anos 1950-1960 como parte do projeto de alavancar o desenvolvimento nacional. Neste contexto, foi criada a Superintendência de Desenvolvimento do Nordeste (Sudene), em 1959, com o objetivo de promover o avanço naquela região do Brasil. O artesanato foi uma de suas frentes de atuação, pensado como mecanismo capaz de aumentar a renda, o trabalho e de melhorar as condições de vida de seus produtores. Para tanto, em 1962, foi criada uma divisão 
especial para cuidar do assunto e a sociedade de economia mista Artene - Artesanato do Nordeste, S. A, cuja atuação sintetiza a proposta de ação institucional sobre o campo.

A Artene pretendia o fomento mercadológico, a assistência técnica e financeira ao artesão e o estímulo à formação de cooperativas. $\mathrm{O}$ artesanato foi classificado em três categorias amplas e ambíguas: artístico, utilitário e remendão que incluíam, sem muita clareza, desde nomes já consagrados como a família Vitalino até ofícios manuais como consertos de sapatos e cadeiras.

Uma reportagem do Jornal do Brasil de 27 de outubro de 1967, intitulada "Artesanato pode ser fonte de divisas", destaca o potencial da Artene como promotora do desenvolvimento social de cerca de 400 mil pessoas ligadas ao artesanato. Informa ainda sobre a criação de lojas e a realização de exposições em São Paulo e capitais nordestinas, além do fomento ao comércio exterior. Critica, no entanto, as condições colocadas para a abertura a um mercado internacional, cujas encomendas eram incompatíveis com o ritmo da atividade artesanal. Apesar disso, outra notícia, do jornal O Globo de 20 de setembro de 1984, "O Nordeste moldado no barro de Caruaru", apresenta Manoel Eudócio como um dos ceramistas brasileiros que mais exportava para os Estados Unidos, exaltando a internacionalização do artesanato brasileiro. Noutra matéria, de 4 de agosto de 1973, do jornal Tribuna da Imprensa, a Artene é descrita como responsável pela comercialização da maior parte dos objetos produzidos no Alto do Moura, PE. Já o texto do Jornal do Brasil de 30 de junho de 1968, "Artesão nordestino já faz da arte um meio de vida", narra as tensões deste processo. A família Vitalino, por exemplo, relata sua falta de interesse em trabalhar com o órgão: "a Cooperativa compra as peças muito baratas, e a gente cobra caro. Foi a nossa família que fundou essa arte - explica Severino".

As cooperativas fomentadas pela Artene deslocaram o indivíduo a um segundo plano, enquanto autor, numa cadeia que organizava o artesanato por tipologias e valores indistintos e baixos. A geração de renda trazia como contrapartida a serialização e interferências estéticas. No mesmo texto do Jornal do Brasil de 30 de junho de 1968 se lê: "Diversos padrões foram redesenhados a fim de que se adequassem ao gôsto [sic] moderno, sem que com isso fosse alterada a sua concepção." A atuação do órgão recebeu crítica contundente de Lina Bardi, de quem falaremos à frente, quanto a seu modelo de gestão e ação ao descrevê-lo como mediano. E ainda a ausência de especialistas em áreas como antropologia, sociologia e economia para construção de dados consistentes citando que "a Artene subsistiu no Recife como lojinha de lembranças para turistas” (Bardi 1994: 62).

Outra instituição relevante alinhada ao discurso desenvolvimentista para o artesanato tradicional é o Serviço Brasileiro de Apoio às Micro e Pequenas Empresas (Sebrae). Oficialmente instituído em 1972, na alçada do Banco Nacional de Desenvolvimento Econômico para apoiar micro e pequenas 
empresas após crises nos anos 1980, foi transformado em entidade privada sem fins lucrativos (Decreto n. ${ }^{\circ}$ 99.570), mantida por repasses empresariais. ${ }^{2}$

A definição de artesanato publicada em seu Termo de Referência (2010) apresenta uma distinção ente arte popular, artesanato e trabalhos manuais (figura 1), embora não explicite claramente como a aplica em relação às quatro categorias de artesanato que elenca: indígena, com ênfase nos valores utilitários e socioculturais; de referência cultural, baseado na releitura de elementos culturais tradicionais; conceitual, associado a um estilo de vida ou afinidade cultural; e o tradicional,

"Conjunto de artefatos mais expressivos da cultura de um determinado grupo, representativo de suas tradições, porém incorporados à sua vida cotidiana. Sua produção é, em geral, de origem familiar ou de pequenos grupos vizinhos, o que possibilita e favorece a transferência de conhecimentos sobre técnicas, processos e desenhos originais. Sua importância e seu valor cultural decorrem do fato de ser depositária de um passado, de acompanhar histórias transmitidas de geração em geração, de fazer parte integrante e indissociável dos usos e costumes de um determinado grupo." (Sebrae 2010)

Paulatinamente o Sebrae construiu uma rede ramificada em todo o país. Sua atuação no campo artesanal tomou fôlego nos anos de 1980 promovendo ações como o "Programa Sebrae de Artesanato para formação do artesão e informação sobre seu produto". Uma de suas iniciativas foi a série de videodocumentários Mestres de Ofícios, cujo objetivo se lê na abertura como: "a formação e a informação que terão papel central não só para educar e orientar os artesãos do presente e do futuro, como igualmente será instrumento importante para divulgar nosso artesanato no próprio Brasil e no exterior" (Sebrae 1988).

\section{Figura 1}

Definição de artesanato do Termo de Referência do Sebrae (2010)

\begin{tabular}{|c|c|c|}
\hline Arte Popular & Artesanato & Trabalhos Manuais \\
\hline Produção de peças únicas & $\begin{array}{l}\text { Produção de pequenas séries } \\
\text { com regularidade }\end{array}$ & Produção assistemática \\
\hline Arquétipo & $\begin{array}{l}\text { Produtos semelhantes, } \\
\text { porém diferenciados entre si }\end{array}$ & Reprodução ou cópia \\
\hline Compromisso consigo mesmo & Compromisso com o mercado & Ocupação secundária \\
\hline Fruto da criação individual & Fruto da necessidade & Fruto da destreza \\
\hline
\end{tabular}

Fonte: Sebrae 2010.

2 Disponível em < https://m.sebrae.com.br/sites/PortalSebrae/canais_adicionais/conheca_quemsom os > (última consulta em janeiro de 2022). 
Essa definição apresenta o tom característico de atuação do Sebrae até à virada do século XX, com discurso semelhante à Artene. Pautou-se na qualificação e adequação do artesanato ao mercado, no empreendedorismo, cooperativismo e intervenção estética. A forma de execução desta última em comunidades tradicionais lhe rendeu críticas como o risco da homogeneização visual e interferência arbitrária em objetos singulares e historicamente reconhecidos (Lima 2010).

Já em 1991, foi criado o Programa do Artesanato Brasileiro (PAB), ligado ao Ministério da Ação Social e, a partir de 2019, à Secretaria de Desenvolvimento da Indústria, Comércio, Serviços e Inovação, do Ministério da Economia. Seu objetivo é potencializar o artesanato em suas especificidades regionais, enquanto atividade econômica promotora do desenvolvimento das comunidades e indivíduos gerando trabalho e renda, favorecendo "a formação de uma mentalidade empreendedora e a capacitação de artesãos para o mercado competitivo, promovendo a profissionalização e a comercialização dos produtos artesanais brasileiros". ${ }^{3}$

Como o Sebrae, o PAB se ramificou desenvolvendo ações por meio de suas superintendências estaduais. Sua definição de artesanato, publicada na Base Conceitual do Artesanato Brasileiro (2012), também tem forte inspiração no documento publicado pelo Sebrae já citado. Repetem-se, com o mesmo teor, as categorias tradicional, indígena, referência cultural, conceitual, acrescendo-se a reciclagem, sublinhando sua dimensão sustentável.

No entanto, o artesanato é descrito num plano intermediário entre a manualidade - baseada em moldes, cópias, com materiais industrializados e sem valor cultural - e a arte popular - distinta por seu "compromisso com a originalidade, o que para o artesão é uma situação meramente eventual” (PAB 2012). A criação para o artesão, segundo o PAB, encontra seu limite quando alcança um modelo satisfatório que passa a reproduzir enquanto "afirmação de sua capacidade de expressão" (PAB 2012). Reforça ainda a hierarquização entre arte e artesanato: "A obra de arte é peça única que pode, em algumas situações, ser tomada como referência e ser reproduzida como artesanato" (PAB 2012).

Essa base conceitual foi atualizada em 2018 por meio da Portaria n. ${ }^{\circ} 1007 / 2018$ do PAB. A arte popular torna-se uma das categorias do artesanato definida pelo caráter individual, autodidata e "reconhecido pelo valor histórico e/ou artístico e/ou cultural, trabalhado em harmonia com um tema, realidade e matéria, expressando aspectos identitários da comunidade ou do imaginário do artista". Uma nova categoria é criada, o artesanato quilombola, "no qual se identifica o valor de uso, a relação social e cultural da comunidade [remanescentes de quilombos]". Por fim, a reciclagem é incorporada ao con-

3 Disponível em < http://www.artesanatobrasileiro.gov.br/pagina/l > (última consulta em janeiro de 2022). 
temporâneo sendo suprimida a hierarquização entre arte, artesanato e manualidade.

Também responsável pela elaboração de políticas públicas em âmbito nacional, o PAB pensa o artesanato num sentido amplo. Tal como as instituições anteriormente citadas, investe no discurso da capacitação, estímulo à comercialização e adequação do produto a um mercado competitivo visando o comércio exterior. Se distingue, no entanto, por buscar uma base conceitual mais elaborada para nortear suas ações.

Com o reconhecimento da profissão do artesão em 2015 (Lei n. ${ }^{\circ}$ 13.180/ /2015), a atuação do PAB ganhou novo fôlego. Criou o Sistema de Informações Cadastrais do Artesanato Brasileiro (Sicab), visando armazenar dados para fomento de políticas públicas. Criou também a carteira do artesão, em 2015, documento que assegura o reconhecimento do seu trabalho e benefícios fiscais, por exemplo. É obtida mediante inscrição que envolve a submissão de objetos produzidos feitos pelo artesão à avaliação institucional sobre sua adequação conceitual ao programa. Igualmente, o PAB emite a carteira do mestre artesão aos que comprovam o reconhecimento e relevância de seu saber, capacidade de transmiti-lo e atuação mínima de dez anos.

\section{O DISCURSO DO DESIGN}

O discurso do campo do design para o artesanato tradicional surgiu atrelado à busca por salvaguardar e fomentar um genuíno desenho brasileiro como traço de distinção identitária e seu potencial econômico. É permeado por percepções sobre diversidade e pluralidade cultural, com forte acento nas soluções encontradas para desenvolver o produto artesanal em suas especificidades regionais. O artesanato é visto como engajamento criativo, valorizando-se a busca pela troca de saberes e linguagens, nomeadamente artesãos, técnicos e acadêmicos, visando um diálogo e refinamento destes objetos sem que percam sua suposta essência. Com a sua disseminação, surgiram também ações não muito equânimes nas interações entre designers e artesãos, sobretudo em relação ao tempo da produção e valores estéticos e simbólicos.

Esta forma de agir discursivamente sobre o artesanato tem como referência dois reconhecidos nomes: Lina Bo Bardi (1914-1992) e Aloísio Magalhães (1927-1982). Ela, arquiteta, designer, curadora e cenógrafa italiana que migra para o Brasil em 1946, fixando-se em São Paulo, cidade em que é autora de projetos icônicos, como o edifício do Museu de Arte de São Paulo (MASP). Em Salvador, foi responsável pela restauração do Solar do Unhão, conjunto arquitetônico do século XVI, que acolheu a transferência do então Museu de Arte Moderna da Bahia e a fundação do Museu de Arte Popular do Unhão, dos quais foi diretora. Ele, pernambucano, pioneiro no campo do design no Brasil, colaborou com a criação da Escola Superior de Desenho Industrial (ESDI), onde 
foi também professor. Realizou obras de impacto público como o símbolo da IV Bienal de São Paulo e as cédulas do cruzeiro (Anastassakis 201 1; Rubino 2002).

Em seu "Discurso sobre a significação da palavra artesanato" (Bardi 2016), Lina o define como um corpo social ativo e atuante em seu meio - tendo por referência as corporações de ofício europeias -, algo que não teria se consolidado no Brasil, atropelado por uma industrialização abrupta e não planejada. Permaneceram, em sua ótica, iniciativas esparsas e algumas manufaturas. Preferia assim, usar o termo pré-artesanato, referindo-se:

"A estrutura familiar de algumas produções como, por exemplo, as rendeiras do Ceará ou os ceramistas de Pernambuco, ocasionais, obrigados pela miséria a este tipo de trabalho, que desapareceria logo com a necessária elevação das rendas do trabalho rural." (Bardi 1994: 28)

No pensamento de Lina Bardi o pré-artesanato era uma alternativa à criação de um design brasileiro amalgamado em sua diversidade cultural e mais adequado às demandas internas. Seu argumento investe a produção nordestina de uma dimensão aurática vista como expressão "pura", alheia às influências da urbanização. Estes objetos, afirma, refletem uma produção indigesta, seca e dura, fruto de um contexto diverso e trágico do ponto de vista econômico e social. Uma potência criativa que deveria ser desvinculada de uma visão reificada de folclore, em prol de valorizar sua dinâmica e atualidade (Bardi 1994).

O projeto de Lina Bardi para o Museu de Arte Popular, em Salvador, incluía um centro de documentação da produção popular, que ofereceria as bases para criação de um desenho industrial brasileiro. Almejava um perfil de formação reunindo mestres artesãos e acadêmicos para troca de conhecimentos e apuro técnico e conceitual de ambos. Com a interrupção de suas atividades em função de sua demissão em 1964, no contexto do golpe militar, tais ações não se concretizaram (Rubino 2002).

Ao longo de sua carreira, Lina realizou várias exposições sobre o artesanato. A Mão do Povo Brasileiro (1969), no MASP, no entanto, foi a de maior repercussão. Reunindo objetos de diversas localidades e tipologias, apresentava um amplo panorama da diversidade da cultura material do país a partir do Nordeste. Ao realizá-la naquele museu (ícone de uma institucionalizada perspectiva de arte), borrava as fronteiras entre arte/artesanato; arte/não arte; artesanato/design. Não por acaso essa mostra foi reeditada em 2016, na mesma instituição, retomando o diálogo do MASP com a produção popular no Brasil (Martins e Pedrosa 2016).

Em outro âmbito, Aloísio Magalhães foi diretor, entre 1975 e 1979, do Centro Nacional de Referências Culturais (CNRC), criado para propor ações intersetoriais que conectassem desenvolvimento econômico, preservação cultural e identidade nacional. Inicialmente constituído por quatro áreas (ciências 
humanas, ciências exatas, documentação, artes e literatura), logo fora reorganizado em torno das categorias: artesanato, levantamentos socioculturais, história das tecnologias e das ciências no Brasil e levantamentos de documentação sobre o Brasil (Clerot 2019). O objetivo era "estudar as formas de vida e atividades pré-industriais brasileiras que estão desaparecendo, documentá-las e, numa outra fase, tentar influir sobre elas, ajudando-as a dinamizar-se" (Magalhães 2017: 135).

Aloísio Magalhães também desconsiderava a existência do artesanato no Brasil no estrito sentido do termo. Destacava, porém, a sua força criativa: "o que nós temos é que observar essa disposição, essa presença muito alta do índice de invenção" (Magalhães 2017: 129). Assim, ele defende o interesse pela capacidade inventiva por detrás de objetos materializados por pessoas que transformam a ausência em algo novo. Documentar e estudar os "índices de invenção" do país antes que a industrialização e massificação desconfigurassem sua genuinidade. Argumenta que o artesão no Brasil estava mais próximo de um potencial designer, e que o mapeamento e fomento dessa produção seriam fundamentais para criação de um design brasileiro. Eventuais interferências, no entanto, deveriam ser cuidadosas, como relata sobre a centenária tecelagem em Uberlândia: "Não iremos alterar o gosto e o comportamento dos tecelões, o que seria perigoso, mas tentaremos mostrar qual o passo que eles devem dar no sentido de uma dinâmica maior." (Magalhães 2017: 136).

Em sua curta existência, o CNRC executou alguns projetos piloto. Um deles inova ao sublinhar a autoria individual - traço nebuloso em um campo que, por longa data, enfatizou o coletivo -, ao documentar o trabalho do ceramista Amaro de Tracunhaém, em Pernambuco. Curiosamente, a ressonância do projeto do CNRC teve um alcance maior do que os resultados sobre o que foi de fato realizado. Lembrado mais por uma memória do que poderia ter sido, do que pelos experimentos que realizou (Dutra 2017).

Em 1979, Aloisio Magalhães assumiu a direção do hoje Instituto do Patrimônio Histórico e Artístico Nacional (IPHAN). Sua gestão foi marcada pela ampliação do discurso sobre patrimônio cultural, calcado na diversidade cultural, superando a ênfase ao barroco e colonial presentes até então. Junto com Mário de Andrade, é lembrado como precursor de uma perspectiva ampliada sobre o tema, que culmina com a atual política do patrimônio imaterial. Sua atuação, no entanto, foi bruscamente interrompida por seu falecimento, em 1982 (Gonçalves 1996).

Desde então, multiplicou-se a atuação de designers junto aos artesãos. Institucionalmente cabe mencionar os debates e mostras realizados por A Casa-Museu do Objeto Brasileiro, em São Paulo, sobre as interações entre design e artesanato. Também em São Paulo foi criado o Pavilhão das Culturas Brasileiras (2010), buscando uma leitura contemporânea sobre as coleções do extinto Museu Rossini Tavares de Lima - processo permeado de polêmicas sobre a 
propriedade do acervo e a autoridade do discurso de folcloristas e de designers sobre o campo artesanal. Puras Misturas, sua exposição inaugural, apresentou ao público a proposta institucional: uma narrativa sobre diversidade cultural brasileira norteada pelo diálogo entre o popular e o erudito; entre o artesanato tradicional e o design.

Outro exemplo é o Sebrae que, a partir de 2010, aproximou-se do design e economia criativa. Sintomático desse movimento foi a criação do Centro de Referência do Artesanato Brasileiro (CRAB), em 2015, uma "plataforma mercadológica para o reposicionamento e a qualificação do artesanato brasileiro, transformando-o em objeto de desejo e consumo e, consequentemente, aumentando seu valor de mercado". ${ }^{4}$ Sua proposta dialoga com os setores de design, arte e moda com um conceito base: "do tripé emoção, conhecimento e comercialização, que, integrados, levam em conta novas conexões, novos modos de viver e apreender o artesanato". ${ }^{5}$ Seguindo tendência crescente no país, são valorizados os objetos que resultam de parcerias entre artesãos e designers considerados de requinte.

Os ecos das ideias de Lina Bardi e Aloísio Magalhães podem ser vistos nos dias atuais em diversas ações e projetos capitaneados por instituições, escritórios de designers, ONG e indivíduos. São projetos que fomentam a interação artesanato/design como um caminho inovador e colaborativo. Há, no entanto, casos em que ainda se nota uma interação distorcida marcada por exotismos, estereótipos e interferências que carecem de um diálogo mais equânime (Borges 2012).

\section{DO DISCURSO SOBRE MEMÓRIAS E SABERES POPULARES}

A terceira matriz discursiva é oriunda do campo de estudos de folclore e cultura popular. Se caracteriza pela busca da genuína identidade nacional materializada em objetos e expressões culturais, interpretados entre o eminente desaparecimento e a renovação contínua entre os anos 1940-1970. A influência da antropologia na passagem dos anos 1970-1980 trouxe uma renovação conceitual com a incorporação de temas como o indivíduo enquanto autor, as significações simbólicas e contexto de sua produção. Se caracteriza também pela preocupação com a salvaguarda, meticulosa documentação e fomento, investindo na criação de um mercado para estes objetos considerando seus valores culturais e evitando intervenções estéticas arbitrárias. Distingue-se das perspectivas anteriores por seu recorte específico em torno do artesanato tradicional. Seu desdobramento recente dialoga com a emergência das políticas voltadas para o patrimônio cultural imaterial. 
Emblemático na ação imbuída neste discurso é o CNFCP, hoje ligado ao IPHAN, que realiza ações de pesquisa, documentação e fomento de expressões populares brasileiras. A instituição tem origem no chamado Movimento Folclórico Brasileiro, na década de 1940, institucionalizado por meio da Campanha de Defesa do Folclore Brasileiro (CDFB), em 1958. A CDFB foi exitosa na promoção de estudos, publicações, congressos e criação de instituições dedicadas ao tema. No âmbito acadêmico, foi alvo de críticas teóricas e metodológicas num momento de acirradas disputas pela consolidação das ciências sociais no Brasil. Estabeleceu, no entanto, um campo de pesquisas aplicadas ao desenvolvimento de políticas públicas para as culturas populares (Vilhena 1997).

Às transformações conceituais que marcam a trajetória do CNFCP, correspondem também distintas perspectivas sobre pensar o artesanato. Nota-se, no entanto, a permanência e atualização de caraterísticas como a preocupação com a documentação, difusão e salvaguarda, assim como uma certa ambiguidade com a categoria arte popular.

A Carta do Folclore Brasileiro (1951), documento basilar das ações do grupo naquele momento, não apresenta uma definição sobre artesanato. Compreende-o como parte do "fato folclórico", este concebido como os modos de pensar, sentir e agir do povo preservados pela tradição popular e livre de influências direta de circuitos exógenos. Destaca, no entanto, a recomendação ao seu fomento, preocupação expressa em documentos e correspondências como a de Renato Almeida, um dos principais articuladores dos folcloristas, para Guilhermo Francovich, então diretor do Centro Regional da UNESCO, sobre a organização do III Congresso Brasileiro de Folclore, realizado em Salvador (1957), cujo tema foi o artesanato:

"Vamos estudar o problema nos seus aspectos técnicos e econômicos, a fim de verificar a forma e a natureza de se poder auxiliar o mesmo, evitando sua regressão em face da invasão da técnica urbana industrializada. Nesse ensejo, faremos uma Exposição de Artesanato em Salvador, que deverá ser o núcleo de um Museu de Artesanato."

A carta indica alguns dos principais caminhos de ação em relação ao artesanato neste momento: evitar sua descaracterização e promover a documentação e salvaguarda por meio de exposições e museus. Neste âmbito, várias instituições foram criadas no país a partir da mobilização da CDFB como o Museu Rossini Tavares de Lima, em São Paulo (1954), e o Museu Édison Carneiro (1968), no Rio de Janeiro, para além de exposições em várias cidades do país.

Uma das mais representativas ações alinhadas a estas premissas conceituais foi o Projeto Artesanato Brasileiro (PAB). Gestado na segunda metade da década de 1970, tinha por objetivo a ampla documentação do artesanato registrando suas técnicas, materiais, locais de produção, enfatizando "a presença e a 
função das peças no âmbito doméstico, lúdico e religioso, mostrando-se, desse modo, as múltiplas dimensões da criação popular" (Funarte 1978: 9).

Conceitualmente, uma publicação sobre o PAB traz uma reflexão de Clarival do Prado Valladares que sublinha as fronteiras turvas entre arte e artesanato, embora afirme que estas estão no âmbito que "une o trabalho de artesania ao trabalho de criatividade" (Funarte 1978: 9). Em termos operacionais, no entanto, o projeto fora concebido classificando o artesanato por materiais: tecelagem, madeira, renda, cerâmica, trançado em fibra, metalurgia e outros. Somente as três primeiras categorias foram efetivamente realizadas, entre meados das décadas de 1970-1980, em função das transformações que ocorreram no CNFCP nos anos seguintes.

A passagem para a década de 1980 é caracterizada por uma reorientação teórica e institucional. A chamada "guinada antropológica" no CNFCP é marcada pela gestão da curadora, museóloga e crítica de arte Lélia Coelho Frota, entre 1982 e 1984. De um lado, ela reflete o impacto das ideias trazidas por um novo quadro de pesquisadores na casa ligados a nomes influentes da antropologia brasileira como Gilberto Velho e Roberto da Matta. De outro, os ecos das ideias de Aloísio Magalhães ao renovar as perspectivas sobre o patrimônio cultural e o artesanato enquanto promotor do desenvolvimento cultural e econômico.

Reflexo deste contexto foi a criação do programa Sala do Artista Popular (SAP), em 1983. Originalmente aberto a distintas expressões das artes populares, ao longo do tempo a dimensão do objeto artesanal em suas fluidas fronteiras entre artesanato tradicional e arte popular predominaram nas ações da SAP. Num texto em que comenta sobre o programa, Lélia Frota (2006: 163) afirma que ele "traz ao público objetos que, por seu significado simbólico e tecnologia de confecção, dão testemunho do viver e do fazer do povo".

A SAP foi desenhada com base na pesquisa etnográfica unindo teoria e ação, atenta à documentação de aspectos simbólicos e estéticos dos objetos, a biografia e o contexto em que vive o artesão, para além de articular parcerias locais visando fomentar e ampliar redes de apoio. Estes dados subsidiam o conteúdo de um catálogo ${ }^{6}$ e culminam com uma exposição com venda aberta ao público. A decisão sobre preços e seleção de objetos cabe aos próprios artesãos. Os custos são subsidiados pelo programa, que repassava os valores das vendas direto aos autores.

Ao longo do tempo a SAP, ainda em atividade, tornou-se uma referência, e ter o seu nome inscrito na lista dos que passaram pelo programa é um reconhecimento do valor de sua obra. De legitimação de indivíduos que produzem bens culturais em geral, à margem de um moderno sistema de arte e cultura

6 Disponível em < http://www.cnfcp.gov.br/interna.php?ID_Materia=176> (última consulta em janeiro de 2022). 
(Clifford 1994). A experiência inspirou também a criação de espaços análogos como sua homônima, criada em 1999, pela Secretaria de Cultura do Paraná.

A expertise desenvolvida com a SAP chamou a atenção do CNFCP para a necessidade de ações que solucionassem as dificuldades de produção e circulação dos objetos. Surgiu assim, em 1996, o Programa de Apoio às Comunidades Artesanais (PACA) que, por falta de recursos, ficou engavetado até que o CNFCP foi procurado pela equipe da então primeira dama do governo de Fernando Henrique Cardoso, a antropóloga Ruth Cardoso (Keller 201 1). Em 1998, Cardoso organizou o Programa Comunidade Solidária de combate à pobreza com vários segmentos de atuação, entre eles o artesanato, e buscava uma metodologia de trabalho. Dessa parceria, Ricardo Lima, então pesquisador do CNFCP recorda:

"A metodologia foi adaptada, funcionou, e chegamos ao modelo que se implantou como Artesanato Solidário. Trabalhamos com 26 comunidades naquela época. O Artesanato Solidário vigorou, como uma ação do governo até o final do governo Fernando Henrique, quando foi transformado numa OSCIP (Organização da Sociedade Civil de Interesse Público), porque dona Ruth temia que, com a mudança de governo, o programa desaparecesse. O ArteSol existe ainda hoje, com sede em São Paulo, e atua em vários pólos artesanais pelo país. [Nós] criamos então, esse novo programa chamado PROMOART [...]." (Keller 201 1: 205).

O Promoart foi realizado entre 2007 e 2018 com o objetivo de encontroar soluções aos entraves da produção artesanal e fomentar sua circulação econômica. Foi pensado para o artesanato tradicional entendido como materialização dos "saberes tradicionais específicos dos quais o artesão é portador", 7 e implantado em 65 polos do país considerados estratégicos para o desenvolvimento de uma política nacional na área. Após a realização de um diagnóstico do estado da arte em cada um deles, foi desenvolvido um projeto específico ajustado às demandas apresentadas pelos artesãos, tendo por base três eixos: apoio ao processo de produção e às redes de escoamento, divulgação e fomento. ${ }^{8}$

O perfil destes projetos indica uma característica própria de ação institucional voltada para a salvaguarda de objetos considerados de valor cultural que se desloca do discurso de perda ao reconhecimento do indivíduo e potência criativa em movimento. Nas últimas décadas somou-se o viés de planejamento de políticas públicas de cultura com um perfil de intervenção pautado nas demandas dos artesãos. Por isso, desde 2007, o CNFCP promove o Encontro

7 Disponível em < http://www.cnfcp.gov.br/pdf/PROMOART/CNFCP_Promoart_folder.pdf $>$ (última consulta em janeiro de 2022).

8 Idem. 
de Artesãos, espaço para debates sobre temas sensíveis à produção artesanal e seus significados, mas, sobretudo, para troca entre eles. É realizado ao fim de um ano de atividades, reunindo todos aqueles que participaram deste ciclo em algum dos programas desenvolvidos pela instituição.

A atualização mais recente desta matriz discursiva surge com a disseminação das políticas voltados para o patrimônio imaterial. Na confluência da presença do artesanato como parte ou associado aos bens culturais reconhecidos, assim como no fomento das leis de reconhecimento de artesãos como patrimônios vivos. Em ambos os casos, no desafio de convergir diferentes programas de modo a potencializar o objeto artesanal.

De modo geral, se o CNFCP inova na perspectiva dialógica, suas ações são consideradas, no limite, conservadoras por alguns atores sociais que atuam no campo do artesanato. Em geral, referem-se ao formato das publicações - distintas dos contemporâneos catálogos de arte e artesanato - e ao modelo de atuação pautado no discurso da memória e salvaguarda, e que encara timidamente questões ligadas ao mercado.

\section{DO DISCURSO SOBRE ARTE POPULAR}

A última matriz discursiva é a que aciona estes objetos como arte popular. Se caracteriza por narrativas de "descoberta" e individualização de sujeitos cujas obras são descritas como expressões únicas de seu imaginário e modo de vida. E ainda por meticulosos processos de colecionamento, escrita biográfica de seus autores e exibição em galerias e museus. Por longa data articulado de forma porosa em relação ao termo artesanato tradicional, em seus desdobramentos recentes nota-se a ênfase na diferença, sobretudo em se distanciar de aspectos como a suposta produção serial e coletiva. A isto se soma a tendência ao alinhamento com o mundo da arte contemporânea questionando, no limite, o qualificativo popular.

Ao longo do século XX, o termo arte popular foi frequentemente utilizado de forma difusa. Exposições e museus criados ou fomentados pela CDFB, por exemplo, receberam a alcunha de arte popular, artes e técnicas populares ou artes e ofícios. Do mesmo modo, Lina Bardi, embora preferisse o termo pré-artesanato, criou um Museu de Arte Popular do Solar do Unhão. O Programa SAP mantém a ambiguidade entre arte popular e artesanato, artista e artesão, como estratégia de atuar no campo de forma abrangente. Com o passar do tempo, no entanto, alguns elementos foram acionados para enfatizar a distinção.

Esse discurso ancora precedentes nas missões de pesquisa realizadas no início do século XX, ecoando os ideais modernistas de urgência pela busca da genuína identidade brasileira (Frota 2005; Lima e Waldeck 2016). São célebres a viagem de Mário de Andrade, nos anos 1920, ao Norte e Nordeste brasileiros e a Missão de Pesquisas Folclóricas, de 1938, idealizada por ele com 
o objetivo de uma ampla recolha documental; e de Hermann Kruse, alemão naturalizado brasileiro, que percorreu o sertão da Bahia e seguiu o curso do Rio São Francisco até ao norte de Minas Gerais recolhendo objetos para o Museu Nacional (Dias 2005; Lima e Waldeck 2016).

Tais missões são ícones das "narrativas de descoberta" das culturas populares no Brasil. Fazem jus à afirmação de João Leal (2009) de que o "popular" surge do encontro daquele que lá estava e aquele que chega e o nomeia como tal. Inicialmente dialogam com discursos de arte e cultura com propósitos estéticos, etnográficos, científicos e políticos. No entanto, elas abrem o caminho para o momento seguinte. $\mathrm{O}$ anseio da descoberta aguça também o interesse de indivíduos por estes objetos vistos como materialização de um genuíno imaginário popular, dando início a um perfil específico de colecionamento da chamada arte popular no país.

Cabe mencionar, por exemplo, a atuação do artista plástico e designer francês Jaques Van de Beuque, que migra para o Brasil em 1946, fixando-se no Rio de Janeiro. Numa viagem de trabalho para Pernambuco, se encantou com os bonecos de barro e a destreza e sensibilidade de seus autores (Mascelani 1999). Essa é a narrativa de descoberta de um ator social que, a partir desse encontro, organizou uma das maiores coleções de arte popular brasileiras e que deram origem ao Museu do Pontal. Precursora de muitas outras, de colecionadores e mercadores, que seguiram percorrendo pequenas cidades do interior em busca de um nome de que se ouviu falar ou da surpresa de algo novo.

Tais buscas e descobertas estão no cerne também de um movimento que ganhou forma no fim dos anos 1960, o surgimento das primeiras galerias dedicadas ao assunto no Brasil. Nega Fulô Artes e Ofícios (1969-1980), no Recife, criada pela pesquisadora Silvia Coimbra; O Bode Galeria de Arte Popular (1972-1992), em São Paulo, de Maureen e Jacques Bisilliart; Pé de Boi (1985 - em atividade), de Ana Maria Schindler, no Rio de Janeiro; Galeria Karandash (1985 - em atividade), em Maceíó, de Maria Amélia Vieira e Dalton Costa; e, mais recente, a Galeria Estação (2004 - em atividade), em São Paulo, pela colecionadora Vilma Eid, que já atuava no campo desde a década de 1980.

Galerias e colecionadores foram cruciais no recorte da arte popular do mundo do artesanato, buscando aproximá-la da arte contemporânea e promover a circulação destes objetos em um mercado dito mais sofisticado. Sobretudo na última década, fomentaram exposições em instituições reconhecidas no campo das artes como Teimosia da Imaginação: Dez Artistas Brasileiros (2012), no Instituto Tomie Othakie, em São Paulo, com itinerância no Paço Imperial (2012), no Rio de Janeiro. Alguns nomes presentes nesta exposição integraram Histoire de Voir (2012), na Fundação Cartier para Arte Contemporânea, em Paris. Mencione-se também a presença destas galerias em feiras como a SP-Arte, e o Art-Rio, buscando dialogar com um contexto internacional e superar as adjetivações e estigmatizações. 
Essa circulação nos mundos de arte, no entanto, não é nova. As fronteiras são turvas desde, pelo menos, a década de 1940. Algumas exposições são emblemáticas, como as organizadas pelo arte-educador Augusto Rodrigues: Cerâmica Popular Pernambucana na Biblioteca Castro Alves, no Rio de Janeiro (1947), considerada um marco de descoberta de Mestre Vitalino. E Arte Popular Pernambucana, no MASP (1949), pioneira do gênero, em São Paulo. Vinte anos depois, o MASP abrigaria a já citada exposição A Mão do Povo Brasileiro. Em 1976, Jaques Van de Beuque organiza uma mostra no Museu de Arte Moderna do Rio (Lima e Waldeck 2016; Mascelani 1999).

Outro aspecto importante foi a produção intelectual sobre o tema. As citadas mostras recentes são acompanhadas por catálogos e material audiovisual. Por um lado, atualizam o debate, valorizando a imagem e um tipo de descrição que se aproxima da crítica de arte contemporânea. Por outro, se somam a uma história da arte popular no Brasil publicada em obras de referência como Riscadores de Milagres: Um Estudo sobre a Arte Genuina, de Clarival do Prado Valladares (1967); O Reinado da Lua: Escultores Populares do Nordeste, de Silvia Coimbra, Flávia Martins e Maria Duarte (1980); Mitopoética de Nove Artistas Brasileiros: Vida, Verdade e Obra e Pequeno Dicionário da Arte do Povo Brasileiro: Século XX, de Lélia Coelho Frota $(1975,2005)$, assim como os catálogos do programa SAP.

O que distingue a circulação atual das experiências anteriores é a ênfase na distinção destes objetos do discurso do artesanato em prol daquele da arte. O processo de artificação (Shapiro e Heinich 2013) aciona no presente o conjunto de exposições, publicações, missões de descoberta enquanto um caminho, um discurso autorizado sobre estes objetos (Smith 2006), já não mais como arte popular mas, por vezes, "arte não erudita" ou, simplesmente, arte. Processo que corresponde também a uma pretensa lapidação: do circuito controlado das galerias em relação ao ordenado caos de feiras; a normatização do valor segundo os ditames do mercado de arte em oposição às negociações isoladas; a representação do artista em contraponto aos inúmeros atravessadores. Talvez uma artificação não conclusa considerando os muitos resquícios de olhares exotizantes e relações de poder muito desiguais ainda a serem superadas.

\section{NOTAS FINAIS}

Olhar "de perto" para o artesanato tradicional nos permite identificar uma categoria em diálogo e disputa entre uma ampla gama de atores sociais. O esforço por qualificá-la nos permite notar como vem sendo retoricamente construída ao longo do tempo e a complexidade de questões que mobiliza. A rede aqui apresentada é parte de um emaranhado circuito de narrativas, colecionamentos, estudos e documentação elaborados por indivíduos, instituições e políticas públicas com entendimentos distintos sobre objetos associados a artesanato e tradição. 
O exercício proposto neste texto foi o de explicitar traços característicos das principais matrizes discursivas que incidem sobre o artesanato tradicional no Brasil, mas que, resguardadas especificidades, pode ser útil para pensar sobre outros contextos. É sabido, no entanto, que na prática tais discursos estão em constante interação, diálogo e tensão. Que uma instituição que se norteia por uma das vertentes apresentadas dialoga e incorpora elementos de outras. Como exemplo, identificamos um conjunto de parcerias entre Sudene, CNFCP e Artesol para a realização de projetos na cidade de Januária, norte de Minas Gerais, nos anos 1990.

Ao analisar as matrizes discursivas apresentadas é possível notar que elas se ancoram em torno de um vocabulário específico. Categorias como arte, artesanato, cultura, memória, indivíduo, coletividade, autoria, mercado, trabalho, renda, design, estética, tradição, patrimônio emolduram e dão corpo aos discursos que são acionados para construir e legitimar formas de agir no mundo a partir do artesanato tradicional ecoando sistemas de pensamentos sobre si e sobre o outro; sobre como um mesmo objeto pode ser classificado e descrito de formas díspares de acordo com a matriz discursiva que o apresenta; e como cada uma das referidas categorias é organizada e hierarquizada com sentidos próprios em cada um destes contextos.

De tal forma, os discursos produzidos sobre objetos chamados de artesanato tradicional configuram sistemas relacionais com sentidos e circuitos de circulação distintos, porém em constante movimento de diálogo. Reverberam diferentes abordagens sobre questões sensíveis neste campo, como o tempo de produção, o impacto de intervenções estéticas, o reconhecimento da autoria e significados destes bens culturais para além da dimensão material, modelos de parcerias e interlocução, bem como os modos de documentar, expor e comercializar.

Se a cada época corresponde um determinado conjunto de conceitos e vocabulário para tentar explicar a experiência humana (Gonçalves 2007), artesanato tradicional é, certamente, um termo atual e relevante no mundo contemporâneo. Retomando a sugestão de Clifford (2004), mais que nunca é uma potente ferramenta para se refletir, articular e criar interconectados futuros. 


\section{BIBLIOGRAFIA}

ANASTASSAKIS, Zoy, 201 1, Triunfos e Impasses: Lina Bo Bardi, Aloísio Magalhães e a Institucionalização do Design no Brasil. Rio de Janeiro: UFRJ, tese de doutorado.

ANDERSON, Benedict, 1991, Imagined Communities. Londres: Verso.

BARDI, Lina, 1994, Tempos de Grossura: O Design no Impasse. São Paulo: Instituto Bardi.

BARDI, Lina, 2016, "Discurso sobre a significação da palavra artesanato", in Adriano Pedrosa e Tomás Toledo (orgs.), A Mão do Povo Brasileiro, 1969/2016. São Paulo: MASP.

BECKER, Howard, 2010, Mundos da Arte. Lisboa: Livros Horizonte.

BORGES, Adélia, 2012, Design+Artesanato: O Caminho Brasileiro. São Paulo: Terceiro Nome.

CANCLINI, Néstor Garcia, 1998, Culturas Híbridas: Estratégias para Entrar e Sair da Modernidade. São Paulo: Edusp.

CARTA DO FOLCLORE BRASILEIRO, 1951, in IBECC - INSTITUTO BRASILEIRO DE EDUCAÇÃO, CIÊNCIA E CUlTURA, Anais do $1 .{ }^{\circ}$ Congresso Brasileiro de Folclore, I Vol. Rio de Janeiro: Ministério das Relações Exteriores: 77-85.

CLEROT, Pedro, 2019, Referência Cultural: Uma Retórica da Descoberta nas Políticas de Patrimônio Cultural. Rio de Janeiro: IPHAN, dissertação de mestrado.

CLIFFORD, James, 1994, "Colecionando arte e cultura", Revista do Patrimônio Histórico e Artístico Nacional, 23 (1994), 69-79.

CLIFFORD, James, 2004, “Traditional futures”, in Mark Phillips e Gordon Schochet (orgs.), Questions of Tradition. Toronto: University of Toronto.

COIMBrA, Silvia, Flávia MARTINS, e Maria Letícia DUARTE, 1980, O Reinado da Lua: Escultores Populares do Nordeste. Recife: Caleidoscópio.

CUNHA, Olivia M.G., 2004, “Tempo imperfeito: uma etnografia do arquivo", Mana, 10 (2). Disponível em < https://doi.org/10.1590/S0104-93132004000200003> (último acesso em janeiro de 2022).

DIAS, Carla, 2005, De Sertaneja a Folclórica: A Trajetória das Coleções Regionais do Museu Nacional, 1920-1950. Rio de Janeiro: UFRJ, tese de doutorado.

DUTRA, Maria Vitória, 2017, Centro Nacional de Referências Culturais: O Desconhecido Acervo Consagrado. Rio de Janeiro: IPHAN, dissertação de mestrado.

FIRJAN - FEDERAÇÃO DAS INDÚSTRIAS DO ESTADO DO RIO DE JANEIRO, 2019, Mapeamento da Indústria Criativa no Brasil. Rio de Janeiro: Firjan.

FROTA, Lélia Coelho, 1975, Mitopoética de Nove Artistas Brasileiros: Vida, Verdade e Obra. Rio de Janeiro: Funarte.

FrotA, Lélia Coelho, 2005, Pequeno Dicionário da Arte do Povo Brasileiro: Século XX. Rio de Janeiro: Aeroplano.

FROTA, Lélia Coelho, 2006, "Imagem e linguagem de objetos-documentos e contexto museal”, in Gilda Santos e Gilberto Velho (orgs.), Artifícios e Artefatos: Entre o Literário e o Antropológico. Rio de Janeiro: 7 Letras, 161-168.

FUNARTE - FUNDAÇÃO NACIONAL DE ARTES, 1978, Artesanato Brasileiro. Rio de Janeiro: Funarte.

GONÇALVES, José Reginaldo, 1996, A Retórica da Perda. Rio de Janeiro: EdUFRJ.

GONÇALVES, José Reginaldo, 2007, Antropologia dos Objetos: Coleções, Museus e Patrimônios.

Rio de Janeiro: Garamond.

HARTOG, François, 2006, “Tempo e patrimônio”, in Varia Historia, 22 (36): 261-273. 
HEYMANN, Luciana, 2013, "Arquivos pessoais em perspectiva etnográfica”, in Isabel Travancas, Joëlle Rouchou e Luciana Heyman (orgs.), Arquivos Pessoais: Reflexões Multidisciplinares e Experiências de Pesquisa. Rio de Janeiro: FGV.

HOBSBAWM, Eric, e Terency RANGER, 2002, A Invenção das Tradições. São Paulo: Paz e Terra.

HOSKINS, Janet, 1998, Biographical Objects: How Things Tell the Stories of People's Lives. Nova Iorque: Routledge.

KELLER, Paulo, 2011, "Artesanato em debate: Paulo Keller entrevista Ricardo Gomes Lima”, Revista Pós Ciências Sociais, 8 (15): 187-210.

KOPYTOFF, Igor, 1986, "The cultural biography of things: commodization as process", in: Arjun Appadurai (org.), The Social Life of Things: Commodities in Cultural Perspective. Cambridge, Cambridge University Express.

LEAL, João, 2009, “Da arte popular às culturas populares híbridas”, Etnográfica, 13 (2): 472-476. DOI: 10.4000/etnografica. 1318

LIMA, Ricardo, 2010, Objetos: Percursos e Escritas Culturais. São José dos Campos: Fundação Cassiano Ricardo.

LIMA, Ricardo Gomes, e Guacira WALDECK, 2016, "Arte popular, mundo de 'descobertas' ", in Adriano Pedrosa e Tomás Toledo (orgs.), A Mão do Povo Brasileiro. São Paulo: MASP.

MAGALHÃES, Aloísio, 2017, “Da invenção e do fazer: o produto brasileiro começa a ter desenhada a sua fisionomia [entrevista]", in João de Souza Leite, Aloísio Magalhães: Bens Culturais do Brasil. Um Desenho Projetivo para a Nação. Rio de Janeiro: Bazar do Tempo, 124:132

MARTINS, Heitor, e Adriano PEDrOSA, 2016, "Introdução", in Adriano Pedrosa e Tomás Toledo (orgs.), A Mão do Povo Brasileiro. São Paulo: MASP, 28-31.

MASCELANI, Angela, 1999, "A Casa do Pontal e suas coleções de arte popular brasileira", Revista do Instituto do Patrimônio Histórico e Artístico Nacional. Rio de Janeiro: IPHAN, 120:155.

NASCIMENTO, Ana, 2016, Relatório do Encontro de Artesãos. Rio de Janeiro: CNFCP.

PAB - PROGRAMA DO ARTESANATO BRASILEIRO, 2012, Base Conceitual do Artesanato Brasileiro. Brasília: PAB.

PAZ, Octávio, 1991, Ver e Usar: Arte e Artesanato. Convergências: Ensaios sobre Arte e Literatura. Rio de Janeiro: Rocco.

PHILlIPS, Mark, 2004, “Introduction”, in Mark Phillips e Gordon Schochet (orgs.), Questions of Tradition. Toronto: University of Toronto.

REIS, Daniel, 2010, Expresões na Madeira: Família Antônio de Dedé. Rio de Janeiro: CNFCP/ IPHAN, catálogo de exposição.

REIS, Daniel, 2018, "Programa Sala do Artista Popular: um espaço de encontros, trocas e democratização de culturas", E-cadernos CES, 30. Disponível em < http://journals. opene dition.org/eces/3924 > (última consulta em janeiro de 2022).

RUBINO, Silvana, 2002, Rotas da Modernidade: Trajetória, Campo e História na Atuação de Lina Bo Bardi. Campinas: Unicamp, tese de doutorado.

SEBRAE - SERVIÇO BRASILEIRO DE APOIO ÀS MICRO E PEQUENAS EMPRESAS, 1988, "Abertura". Cláudio Assis . Barro em Pernambuco. Vídeo, SP: Sebrae.

SEBRAE - SERVIÇO BRASILEIRO DE APOIO ÀS MICRO E PEQUENAS EMPRESAS, 2010 , Termo de Referência: Atuação do Sistema Sebrae no Artesanato. Brasilia: Sebrae. 
SENNETT, Richard, 2009, O Artífice. Rio de Janeiro: Record.

SHAPIRO, Roberta, e Nathalie HEINICH, 2013, “Quando há artificação?”, Revista Sociedade e Estado, 28 (1): 14-28.

SMITH, Laurajane, 2006, Uses of Heritage. Londres: Routledge.

VALLADARES, Clarival, 1967, Riscadores de Milagres: Um Estudo sobre a Arte Genuina. Rio de Janeiro: Vida Doméstica.

VILHENA, Luís R., 1997, Projeto e Missão: O Movimento Folclórico Brasileiro. Rio de Janeiro: Funarte/FGV.

Receção da versão original / Original version

$2020 / 10 / 22$

Receção da versão revista / Revised version

$202 \mathrm{l} / \mathrm{l} \mathrm{l} / 30$

Aceitação / Accepted

$2022 / 01 / 21$ 